\title{
Tobacco tax evasion in Western Balkan countries: tax evasion prevalence and evasion determinants
}

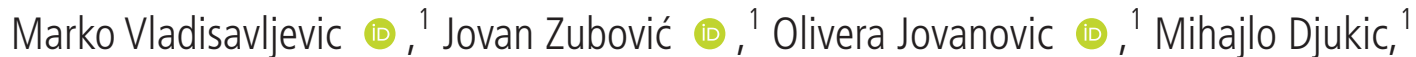 \\ Natasa Trajkova Najdovska, ${ }^{2,3}$ Ereza Pula, ${ }^{4}$ Dragan Gligorić, ${ }^{5}$ Aida Gjika ${ }^{6,7}$
}

\begin{abstract}
- Additional supplemental material is published online only. To view, please visit the journal online (http://dx.doi. org/10.1136/tobaccocontrol2021-056879)
\end{abstract}

'Institute of Economic Sciences, Beograd, Serbia

${ }^{2}$ Faculty of Economics, University St Kliment Ohridski, Bitola, Macedonia

${ }^{3}$ Analytica Think Tank, Skopje, Macedonia

${ }^{4}$ Prishtina, Albania

${ }^{5}$ Faculty of Economics, University of Banja Luka, Banja Luka, Bosnia and Herzegovina

${ }^{6}$ Faculty of Economics, University

of Tirana, Tirana, Albania

Development Solution

Associates, Tirana, Albania

\section{Correspondence to}

Dr Marko Vladisavljevic, Institute of Economic Sciences, Belgrade 11000, Serbia;

marko.vladisavljevic@ien.bg. ac.rs

Received 29 June 2021

Accepted 29 November 2021

Check for updates

(c) Author(s) (or their employer(s)) 2022. No commercial re-use. See rights and permissions. Published by BMJ.

To cite: Vladisavljevic $\mathrm{M}_{\text {, }}$ Zubović J, Jovanovic 0 , et al. Tob Control Epub ahead of print: [please include Day

Month Year]. doi:10.1136/

tobaccocontrol-2021-056879

\section{ABSTRACT}

Background and objective Tobacco tax evasion undermines the goal of tobacco taxes as a tobacco control measure to make tobacco products less affordable, increases the health risks for those who smoke and decreases the government revenue. This paper analyses the tobacco tax evasion in six Western Balkan (WB) countries: Albania, Bosnia and Herzegovina, Kosovo, Montenegro, North Macedonia and Serbia. The aim of this research is to estimate the size of the illicit market and identify the main determinants of tax evasion activities in the Southeastern European region.

Data and methods Data from 2019 Survey on Tobacco Consumption in Southeastern Europe (STCSEE) are used. STC-SEE provides uniquely comparable nationally representative data on smoking behaviour for adult (18-85 years old) population for each country. Tax evasion is defined on the basis of available information on tax stamps, health warnings, price and the place of purchase, in accordance with the previous research on tax evasion. In order to estimate the determinants of illicit purchases we use binary choice model of tax evasion.

Results The study finds that $20.4 \%$ of all current smokers in WB countries evade taxes on tobacco products, with evasion being much more frequent for hand-rolled (HR) tobacco $(86.7 \%)$ than for the manufactured cigarettes (MC) $(8.6 \%)$. While HR is predominantly illicit in all six countries, MC evasion varies significantly, with evasion being significantly higher in Montenegro and Bosnia and Herzegovina. Results further suggest that tax evasion is higher in the statistical regions where institutional capacities to tackle illicit trade are lower, in municipalities bordering countries with high $\mathrm{MC}$ evasion, as well as among smokers with low income, women and elderly. We also provide evidence that higher tobacco taxes and prices do not increase illicit consumption.

Conclusion The findings from the research suggest that in order to decrease tax evasion, governments should put additional effort to strengthen institutional capacities to tackle illicit tobacco markets. Furthermore, improving regional coordination in development and implementation of tobacco control policies, including the prevention of illicit market, is essential in lowering evasion in all WB countries. Finally, WB countries should regulate and enforce excise tax stamp requirements on the HR tobacco market to a much higher degree.

\section{INTRODUCTION}

Research on tobacco tax evasion is highly a relevant policy issue for at least two reasons. First, tax evasion has numerous adverse implications for both public health and economy. In 2010, Joossens et $a l^{1}$ estimated the illicit share of the global tobacco market at $11.6 \%$ and the annual global revenue loss related to illicit tobacco of more than US $\$ 40$ billion. A more recent study by Goodchild et $a l^{2}$ estimates this share at about $11.2 \%$. On the other hand, tax evasion increases the health risks for those who smoke illicit cigarette packs, since they usually do not present important information about the harmful effects of tobacco use, ${ }^{3}$ while at the same time diluting tobacco taxation policy objective to make tobacco products less affordable. ${ }^{4}$

The second reason stems from the tobacco industry claims that tax evasion activities arise primarily as a consequence of tax increases and differences in tax rates and prices between countries, ${ }^{5}$ as opposed to institutional deficiencies and complex tax structures. This argument of the tobacco industry has frequently been used as an argument for low tobacco taxes and used as a tool for lobbying by the tobacco industry. ${ }^{6}$ However, contrary to the arguments of the industry, global data show that illicit trade is higher in countries with a lower share of the tax margin. ${ }^{7}$ Joossens $\mathrm{et} \mathrm{al}^{3}$ conducted the largest independent study on illicit trade in Europe and found no evidence to support a relationship between the price of tobacco products and the size of the illicit market. In fact, their findings indicate that the share of illicit trade is likely to be higher in countries where the prices are lower. The UK's experience also confirms that raising tobacco taxes was not followed by an increase in tax evasion ${ }^{8}$ : the share of the illicit market in the UK decreased from $30.9 \%$ in 2000 to $21 \%$ in 2010 , despite recorded tobacco tax increases (derived from UK government reports: Measuring Tax Gaps 2000-2010. ${ }^{9}$ These research and existing literature suggest that there are many determinants of tax evasion other than price, including tobacco products' affordability, corruption, informal distribution networks, etc. ${ }^{10}$

This study aims to provide the first comparable evidence on the size and determinants of the illicit tobacco market in the Western Balkan (WB) countries by analysing tobacco tax evasion for the two products with the highest prevalence in the WB region: manufactured cigarettes (MC) and handrolled (HR) tobacco. The study uses unique nationally representative data from STC-SEE, collected during September and October 2019 in six WB countries: Albania, Bosnia and Herzegovina (BiH), Kosovo, Montenegro, North Macedonia and Serbia. The analysis of determinants is based on a quantitative approach and we draw conclusions 
based on the econometric model and the available data, while some factors such as the impact of tobacco industry's potential complicity in smuggling practices cannot be assessed.

Our results indicate that $20.4 \%$ of all smokers in WB countries are smoking tobacco products on which the taxes have not been paid. Tax evasion is much more likely among HR smokers at $86.7 \%$, while only $8.6 \%$ of MC smokers smoke illicit tobacco. The predominant type of HR evasion is the so-called 'genuine DNP' (duty not paid) where both tax stamp and health warning are missing, while at the same time purchased on the street or open air markets. On the other hand, for the MC evasion, the predominant type is the so-called illicit whites, where health warnings, typically in foreign language, are present while tax stamps are missing, suggesting that the source of this type of evasion was smuggling across the border. The terms 'genuine DNP' and 'illicit whites' are used in accordance with the data at our disposal. We label the package as 'genuine DNP' if it has no health warning or tax stamp, and assume that no taxes have been paid on it by the producer or by consumer of tobacco products. We label the package as 'illicit white' if it has health warning, but it does not have a tax stamp, as we assume that they are produced legally, but smuggled or distributed via other illegal channels, and sold illegally. Although these terms can be operationalised differently, we see them as the best fit to label different groups of illicit tobacco products that we find in our data.

While HR evasion varies relatively little across countries, MC evasion levels are strikingly different, with the highest shares of MC smokers who smoke illicit cigarettes in Montenegro and $\mathrm{BiH}-61.2 \%$ and $18.6 \%$, respectively. In all other countries, the share of MC smokers who smoke illicit cigarettes is below 6\%. The results further suggest that tobacco tax evasion is higher in the statistical regions, where the share of non-street illicit purchases of MC in total illicit MC purchases is higher, as well as in municipalities in close proximity to borders with countries that have high evasion rates. Furthermore, the results suggest that smokers from low-income households, women and the elderly tend to evade tobacco taxes more. Finally, similar to Joossens $e t ~ a l,{ }^{3}$ we find that the prices have no effect on tobacco tax evasion, therefore providing further evidence that higher tobacco taxes and prices do not increase illicit consumption, contrary to tobacco industry claims.

Estimating the size of the illicit market and its determinants is of particular relevance for the WB region. First, all six WB countries have a relatively high prevalence of tobacco use. ${ }^{11}$ Taking into account experiences from other European countries-the latest European Union (EU) member states in particular-it is expected that raising taxes as a part of tobacco control reform will be attacked by opponents of tobacco taxes as an ineffective and harmful policy measure that stimulates tax evasion and reduces fiscal revenues, ${ }^{12}$ as it was the case prior to adoption of the EU Tobacco Products Directive (2014/40/EU).

Second, the WB region has a rich history of illicit purchasing of tobacco products, particularly during the period of economic turmoil in the 1990s. ${ }^{13-15}$ In this regard, Southeastern European residents are quite accustomed to black market purchase patterns and the channels of illicit trade. Third, institutions and law enforcement that are crucial for the elimination of the illicit market in WB countries are still underdeveloped. ${ }^{16}{ }^{17}$ Government authorities that are already not capable of controlling illicit trademay be reluctant to increase taxes out of fear of rising tax evasion. WHO Framework Convention on Tobacco Control (FCTC) Protocol to Eliminate Illicit Trade in Tobacco Products has been signed by Serbia and Montenegro among the WB countries. North Macedonia signed the Protocol but has not yet become a Party, whereas Albania, $\mathrm{BiH}$ and Kosovo have not yet signed on. Data presented in this paper confirm difficulties in implementation of the Protocol.

This paper is structured as follows. After the introduction, the Data and methods used section describes the data sources, explains the construction of the tax evasion variables, and the econometric method used in the tax evasion model which estimates the determinants of tax evasion. The Results: descriptive statistics on illicit tobacco consumption section provides descriptive statistics including the main indicators of illicit markets in the WB region and a discussion of potential determinants of tax evasion, while the results of the tax evasion model are presented in the Results from the estimation of the tax evasion models section. The Discussion and conclusions section discusses the main results of the analysis, and presents conclusions and recommendations for policy makers and some limitations of the analysis.

\section{DATA AND METHODS USED \\ Data and the definition of illicit tobacco consumption}

This study uses STC-SEE data, uniquely comparable data on tobacco consumption and its characteristics in WB region, conducted in 2019, which uses the same questionnaire (questionnaire is largely based on and comparable with Global Adult Tobacco Survey (GATS)) and survey methodology in all countries surveyed. Along with detailed information on tobacco consumption, tax stamps, health warnings, prices of cigarettes and places of purchase, STC-SEE provides photographs of the last purchased cigarette/tobacco pack, as well as specific sociodemographic characteristics of the respondents. The sample size was 1000 respondents per country, with the exception of Serbia where 2000 respondents were interviewed. Data collection was coordinated by Deep Dive—a private, independent, full-service social and market research consulting firm. Deep Dive is a European Society for Opinion and Marketing Research member.

The definition of illicit tobacco is challenging for many reasons; however, in most of the cases researchers agree on the criteria of estimation. In WHO's reports on tobacco consumption from GATS, a standard survey in the literature, the source of cigarette purchases (from street vendors) and the absence of tax stamps and health warnings on cigarettes were used as an indicator of illicit trade. ${ }^{18-22}$

Joossens $e t a^{3}$ conducted the largest independent study on illicit trade in Europe. In their definition of the illicit tobacco, they use identification of an illicit pack (IIP) method that is based on the same criteria: place of purchase, presence of tax stamp and health warning, while adding low price criteria to the list. They estimated the level of illicit trade in Europe as below 7\% on average, varying significantly between countries, and with the larger share belonging to countries with a land or sea border with Ukraine, the Russian Federation, Moldova or Belarus. ${ }^{2}$

Stoklosa and Ross ${ }^{23}$ use similar criteria as Joossens $e t a^{3}$ and apply two observational methods (collection of packs shown by tobacco users and collection of packs discarded on the street) to estimate the share of non-taxed cigarettes in Poland. They found the illicit share of the tobacco market to be $14.6 \%$ and $15.6 \%$, respectively-significantly lower than industry estimates amounting to $22.9 \%$ of the market. Their findings support the thesis that the industry tends to overestimate the size of tax evasion.

In this research, in defining the illicit tobacco consumption, we follow Joossens et al. ${ }^{3}$ Following their IIP definition, in this paper tax evasion is defined in accordance with the rule that the 
pack is illicit if it has at least one of the following four characteristics: (1) purchased from an illicit source, (2) without the appropriate health warnings, (3) without the appropriate tax stamp, or (4) purchased at a price lower than $70 \%$ of the lowest price. For HR tobacco, the price of the cigarette pack was not available; therefore, the definition of tax evasion was based only on the first three criteria. As legal definitions of tax evasion can be different in different WB countries, researchers from each country were in charge of the definition of the tax evasion variables (annex 2, online supplemental file 1). The observational method was applied in all countries; numerators took pictures of the last purchased tobacco pack shown by tobacco users and recorded data on tax stamps, health warnings, place of purchase and reported price per pack. If the respondent was not able to show the last pack purchased, she/he was asked to recall the pack and provide information on the tax stamp and health warnings.

To estimate the potential effect on tax evasion of being in close proximity to a neighbouring country with lower prices or higher tax evasion rates, driving distances between each municipality in the country and all bordering countries (border crossings nearest to the municipality) were collected via Google Maps.

\section{Estimation of the tax evasion model in the WB region}

In order to analyse the determinants of tax evasion, a binary choice model of tax evasion is applied. Formally, the model can be represented in the following way:

$$
\begin{gathered}
P\left(\text { evasion }_{i}=1\right)= \\
=f\left(\beta_{1} p_{r}+\beta_{2} \text { NSIP }_{r}+\beta_{3}^{\prime} \text { Proximity }_{m}\right. \\
+\gamma^{\prime} X_{i}+\delta^{\prime} \text { Country }_{i}
\end{gathered}
$$

where the probability of tax evasion (for MC, HR or total tax evasion) is the function of the determinants on the righthand side of the equation: the average s-regional price of legally sold cigarettes $\left(\mathrm{p}_{\mathrm{r}}\right)$, the s-regional percentage of non-street illegal purchases in total illegal purchases $\left(N S I P_{r}\right)$, a set of dummy variables representing whether or not the municipality is in close proximity to another country (Border $\left.{ }_{m}\right)$ and a set of socioeconomic (education, income group) and demographic variables $\left(X_{i}\right.$ ). The s-regional variation of the price and NSIP indicator within the region is used in order to estimate the model. Therefore, s-regional averages of prices and NSIP are used in the analysis. NSIP variable is explained in more detail in the Tax evasion in WB countries and other country characteristics section.

The s-regional average legal prices are used for two reasons. First, to estimate a tax evasion model, legal prices need to be observed for both smokers who purchase their cigarettes illicitly and legally. Second, prices at the s-regional level strengthen their exogeneity in comparison to the tax evasion decision. There is a large consensus that the impact of the prices of tobacco demand (and illicit demand) is exogenous as tobacco prices are largely determined by the size of taxes (excises) on tobacco, transportation and other distribution costs and not by demand side effects. This argument is further strengthened in our research by the fact that legal tobacco prices are calculated on s-regional level, while the likelihood of illicit consumption is provided on the individual level. Due to this, reversed causality is not likely as individual-level decisions have little or no effects on s-regionallevel variables. Persons living in s-regions with higher prices are expected to have higher incentives for tax evasion. The share of NSIP indicates the lack of control over legal establishments that would prevent them from engaging in non-legal activities, and as such higher levels of this indicator are expected to increase tax evasion.

In order to estimate the effect of the proximity to countries with lower cigarette prices and countries with significantly (by
10 percentage points) higher MC evasion rates, driving distances to the nearest border crossing are used. Municipalities are assumed to be in close proximity if their border is up to $50 \mathrm{~km}$ away from the border crossing with a country that has lower prices or a higher MC tax evasion rate. Country differences in $\mathrm{MC}$ tax evasion are used rather than the overall tax evasion rates as $\mathrm{HR}$ products are typically illegal in all the WB countries, and therefore they would only confound the differences in MC tax evasion rates. The border dummy variables take the value of 1 if the municipality is in close proximity to lower price or higher evasion border countries, and 0 if otherwise. Additionally, as the municipalities closer to the border may be less developed than central municipalities, an additional dummy variable is used as a proxy for living close to any border. This variable takes the value of 1 if the municipality's driving distance to any border crossing is shorter than $50 \mathrm{~km}$, and 0 if otherwise. This approach is similar to the study of Driezen ${ }^{24}$ who investigates cross-border purchases in relation to the geographical location of the region.

Personal and household characteristics included in the model $\left(X_{i}\right)$ consist of age, age squared, gender, level of education with three categories : primary education (which includes International Standard Classification of Education (ISCED) groups $0-2$ ), secondary education (ISCED groups 3 and 4 ) and tertiary education (ISCED groups 5-8), type of residence (rural vs urban) and household income per capita, in order to account for household differences in purchasing power. The master questionnaire includes a scale of 11 income categories and is expressed in euros. During the data collection process, these intervals were transformed to local currencies, and the respondents chose based on local currency intervals. As the data contain a large number of missing values, intervals are imputed based on other personal and household characteristics in order to avoid sample attrition. As the income variable was recorded in intervals rather than exact amounts, the average of the interval was calculated and divided by the number of household members to obtain a household welfare measure. The variable obtained in this way was then divided into three equal groups (low, middle and highincome households) in each country.

Finally, the model includes country-fixed effects (Country $\left.{ }_{i}\right)$ to account for the remaining unobserved country heterogeneity (not controlled by other variables). Additionally, s-regional cluster-corrected SEs are applied to account for the fact that prices and the per cent of NSIPs are defined at higher levels of aggregation, while potential heteroscedasticity is controlled by calculating heteroscedasticity-robust SEs. Finally, function $f$ in the model is approximated by the logit function.

\section{RESULTS: DESCRIPTIVE STATISTICS ON ILLICIT TOBACCO CONSUMPTION}

\section{Consumption of HR and MC and illicit trade}

Overall, North Macedonia has the highest smoking prevalence rate of all WB countries at $48.9 \%$, while prevalence is lowest in Albania at $24.7 \%$ (table 1 , column 5). Since in all WB countries, smokers predominantly use MC, the sample for the estimation of $\mathrm{MC}$ tax evasion is much larger than for HR evasion.

The data suggest that there are striking differences across the WB region in the share of illicit MC users. The share of MC tax evasion is highest in Montenegro (61.2\%), three times as high as the next highest share in $\mathrm{BiH}(18.6 \%)$. In other countries, MC tax evasion is relatively low-below 6\%-the lowest being in North Macedonia at $1.9 \%$. On average, the share of MC users who purchase their products illicitly in the WB region stands at $8.6 \%$, mainly due to high tax evasion in Montenegro and $\mathrm{BiH}$. 
Table 1 Prevalence of smoking and share of smokers evading taxes (MC, HR and total, in per cent)

\begin{tabular}{|c|c|c|c|c|c|c|}
\hline \multirow[b]{2}{*}{ Country } & \multicolumn{2}{|c|}{ Manufactured cigarettes } & \multicolumn{2}{|c|}{ Hand-rolled tobacco } & \multirow[b]{2}{*}{$\begin{array}{l}\text { Total smoking } \\
\text { prevalence* }\end{array}$} & \multirow[b]{2}{*}{$\begin{array}{c}\text { Total tax evasion } \\
\text { prevalence }\end{array}$} \\
\hline & $\begin{array}{c}\text { Smoking } \\
\text { prevalence }\end{array}$ & $\begin{array}{l}\text { Tax evasion } \\
\text { prevalencet }\end{array}$ & $\begin{array}{c}\text { Smoking } \\
\text { prevalence }\end{array}$ & $\begin{array}{c}\text { Tax evasion } \\
\text { prevalencet }\end{array}$ & & \\
\hline & (1) & (2) & (3) & (4) & (5) & (6) \\
\hline Albania & 19.8 & 5.2 & 6.0 & 69.2 & 24.7 & 19.4 \\
\hline Bosnia and Herzegovina & 33.9 & 18.6 & 9.7 & 93.3 & 41.9 & 35.3 \\
\hline Kosovo & 35.6 & 4.2 & 1.4 & $79.3 \ddagger$ & 36.7 & 7.1 \\
\hline Montenegro & 38.8 & 61.2 & 2.9 & $100 \ddagger$ & 41.0 & 62.6 \\
\hline North Macedonia & 44.5 & 1.9 & 6.1 & 86.7 & 48.9 & 12.3 \\
\hline Serbia & 32.8 & 2.6 & 6.3 & 88.2 & 37.4 & 14.8 \\
\hline WB region & $32.8 \S$ & $8.6 \pi$ & $6.3 \S$ & 86.79 & $37.6 \S$ & $20.4 \pi$ \\
\hline
\end{tabular}

Source: Authors' calculations based on the Survey on Tobacco Consumption in Southeastern Europe (STC-SEE) data.

*The sum of MC and HR prevalence does not add up to total prevalence, as some smokers use both products.

tRepresents the percentage of smokers who evade tax on cigarettes.

¥Estimates are not reliable due to a small sample size $(n<15)$.

$\S$ The average prevalence rate for the region is calculated as the number of smokers ( $\mathrm{MC}+\mathrm{HR}$, based on national prevalence rates) divided by the total number of persons living in the WB region.

१The average share of smokers who evade taxes for the region is calculated as the total number of smokers who evade in the WB region (based on national tax evasion shares) divided by the total number of smokers in the WB region.

$\mathrm{HR}$, hand rolled; MC, manufactured cigarette; WB, Western Balkan.

Overall, the predominant type of MC evasion was classified as 'illicit white', as in about $78 \%$ of the cases the MC pack had a health warning (majorly in foreign language), but did not have a tax stamp. Additionally, in about $15 \%$ of the cases, the pack was classified as a 'genuine duty not paid (DNP)' as not having either a tax stamp or a health warning, while in about $7 \%$ of the cases, MC had both tax stamp and health warning but it was not purchased from the legal place (ie, on the street or open air market).

On the other hand, HR tobacco tax evasion is very high in all countries, the lowest being in Albania with about 69.2\%, while in all other countries the rate of tax evasion is higher than 80\% (in Montenegro, all registered HR users are tax evaders although the sample size of HR users in Montenegro is small13). On average, $86.7 \%$ of HR smokers in the WB region use illicit tobacco. Contrary to the MC, the predominant type of HR evasion is a 'genuine DNP' (without health warning or tax stamp), with $82 \%$ of all HR evasion cases. These packages did not have either a tax stamp or a health warning and were sold on the street or open air market. 'Illicit whites' (with health warning but without a tax stamp) make only about $7 \%$ of total HR evasions, while the remaining $11 \%$ had both tax warnings and stamps, but were purchased from illegal place (ie, on the street or open air market).

In total, for both products, the average share of smokers who evade taxes in the WB region amounts to $20.4 \%$ (column 6), with the share being the lowest in Kosovo and the highest in Montenegro.

Additionally, STC-SEE data indicate that smokers of legal and illicit tobacco products generally do not differ in the intensity of their smoking. Therefore, tax evasion rates, that is, the overall size of illicit consumption in countries, roughly correspond to the evasion prevalences presented in table 1 .

\section{Tax evasion in WB countries and other country characteristics}

Table 2 presents shares of MC and HR smokers who evade taxes compared with the average prices of different tobacco products. According to both market and survey data, the most expensive MCs purchased legally are in $\mathrm{BiH}$ and Montenegro, while the

Table 2 Prices of legal versus illicit MC and HR, and prevalence of tax evasion in the WB region

\begin{tabular}{|c|c|c|c|c|c|c|c|}
\hline \multirow[b]{2}{*}{ Country } & \multirow{2}{*}{$\begin{array}{l}\text { MC smokers who } \\
\text { evade (\%) }\end{array}$} & \multirow{2}{*}{$\begin{array}{l}\text { HR smokers who } \\
\text { evade (\%) }\end{array}$} & \multicolumn{2}{|c|}{$\begin{array}{l}\text { MC market prices } \\
\quad \text { (in } €, 2019)\end{array}$} & \multicolumn{3}{|c|}{$\begin{array}{l}\text { Average prices from STC-SEE } \\
\text { (in } €, 2019)^{*}\end{array}$} \\
\hline & & & Cheapest brand & Most sold brand & Legal MC $\mathrm{M}^{+}$ & Illicit MC† & HR \\
\hline & (1) & (2) & (3) & (4) & (5) & (6) & (7) \\
\hline Albania & 5.2 & 69.2 & 1.6 & 1.9 & 2.1 & $1.9 \S$ & 0.9 \\
\hline Bosnia and Herzegovina & 18.6 & 93.3 & 2.3 & 2.4 & 2.7 & 1.7 & 1.0 \\
\hline Kosovo & 4.2 & $79.3 \S$ & 1.7 & 2.1 & 2.0 & 1.7 & $0.9 \S$ \\
\hline Montenegro & 61.2 & $100.0 \S$ & 1.9 & 2.3 & 2.5 & 1.5 & $0.6 \S$ \\
\hline North Macedonia & 1.9 & 86.7 & 1.3 & 1.5 & 1.5 & $1.4 \S$ & 1.1 \\
\hline Serbia & 2.6 & 88.2 & 1.7 & 2.1 & 2.3 & $1.7 \S$ & 1.0 \\
\hline
\end{tabular}

Source: Market prices: Albania—WHO Report on the Global Tobacco Epidemic (2019); B\&H—Indirect Taxation Authority of Bosnia and Herzegovina; Kosovo—Agency of

Statistics Reports; Montenegro-Tobacco Agency of Montenegro; North Macedonia—Customs Administration (not publicly available, obtained following a request); SerbiaOfficial Gazette of the Republic of Serbia (No 27/2019 and 66/2019). Other data: Authors' calculations based on the STC-SEE data.

* Simple average.

tSelf-reported price of the last pack purchased.

‡Calculated as a median unit value for $20 \mathrm{HR}$ cigarettes. Unit value is a ratio between total weekly expenditure on HR and weekly consumption of HR cigarettes.

$\S$ Estimates are not reliable due to a small sample size.

HR, hand rolled; MC, manufactured cigarette; STC-SEE, Survey on Tobacco Consumption in Southeastern Europe; WB, Western Balkan. 
Table 3 Prevalence of MC and HR tax evasion and percentage of non-street illegal purchases

\begin{tabular}{lccc}
\hline Country & $\begin{array}{l}\text { MC smokers who } \\
\text { evade taxes (\%) }\end{array}$ & $\begin{array}{c}\text { HR smokers who } \\
\text { evade taxes (\%) }\end{array}$ & $\begin{array}{c}\text { Non-street illicit } \\
\text { purchases (\%)* }\end{array}$ \\
\hline Albania & 5.2 & 69.2 & 10.4 \\
$\begin{array}{l}\text { Bosnia and } \\
\text { Herzegovina }\end{array}$ & 18.6 & 93.3 & 14.8 \\
Kosovo & 4.2 & & 68.9 \\
Montenegro & 61.2 & $79.3 \dagger$ & 33.7 \\
North Macedonia & 1.9 & $100 \dagger$ & 14.2 \\
Serbia & 2.6 & 86.7 & 11.1 \\
\hline
\end{tabular}

Source: Authors' calculations based on the STC-SEE data.

*Share of smokers who purchase illegally in places other than street or open market. The denominator in the third column - the total number of people who purchase their products illegally is different from the denominator in columns 1 and 2 (total number of smokers).

tEstimates are not reliable due to small sample size.

HR, hand rolled; MC, manufactured cigarette; STC-SEE, Survey on Tobacco

Consumption in Southeastern Europe.

cheapest MCs in the region are in North Macedonia. Given as a purely descriptive statistic this result would indicate that in countries in which MC evasion is the highest cigarette prices are also the highest; however, in the Results from the estimation of the tax evasion models section, the independent effect of these prices is estimated in a regression model. On the other hand, the differences in the average prices of illicit MC and HR prices are less pronounced, and for some countries they are based on low number of observations and cannot be reliably measured. Therefore, the only reliably measured and salient difference between the countries is in the prices of legal cigarettes, and this variable will be used in the model in the Results from the estimation of the tax evasion models section.
Table 3 presents the share of non-street (ie, legal point of sale) purchases of illicit cigarettes among the total number of illicit purchases in the s-region (NSIP). In other words, these are the purchases in legal establishments such as legal tobacco shops, cafes and restaurants which are illicit according to other criteria (no tax stamp, no health warning or low price). The indicator ranges from $0 \%$ (no illicit purchases occur at legal points of sale) to $100 \%$ (all the purchases are at legal points of sale), and a higher share may indicate that the government has a problem preventing legal establishments from engaging in non-legal tobacco-related activities in that s-region. The highest shares of illicit purchases at legal points of sale are in Kosovo and Montenegro, and the lowest in Albania and Serbia. It is worth noting that the law in Kosovo does not specify the legal points of sale for tobacco; however, this indicator is still relevant there as it shows the share of illegal purchases in the places where tax authorities typically have higher level of control of the products sold. Although the correlation is not as clear as for the prices, the figures in table 3 indicate that countries with higher evasion rates also have higher shares of NSIPs. However, in the next section, we include both of these characteristics in the econometric model to analyse if they have a statistically independent impact on the likelihood of evasion.

\section{RESULTS FROM THE ESTIMATION OF THE TAX EVASION MODELS}

Table 4 presents the estimation of the MC tax evasion model in the WB region. Several different specifications (S1-S3) are presented, and conclusions are derived by comparing the results of the different models. Specification S1 estimates the model presented in equation (1) on full sample, while in specification $\mathrm{S} 2$ we exclude Montenegro and $\mathrm{BiH}$ as countries with significantly higher MC tax evasion rates to check the robustness of

Table 4 MC tax evasion model

\begin{tabular}{|c|c|c|c|c|c|c|}
\hline \multirow[b]{2}{*}{ Variables } & \multicolumn{2}{|c|}{ S1 } & \multicolumn{2}{|c|}{ S2 } & \multicolumn{2}{|c|}{ S3 } \\
\hline & Coefficient & SE & Coefficient & SE & Coefficient & SE \\
\hline Price (legal MC) & -0.412 & $(0.359)$ & 0.068 & $(0.126)$ & -0.571 & $(0.372)$ \\
\hline$\%$ NSIP & $0.138^{*}$ & $(0.084)$ & $0.528 * * *$ & $(0.141)$ & $0.159^{*}$ & $(0.089)$ \\
\hline Urban & -0.000 & $(0.013)$ & $0.015^{* *}$ & $(0.008)$ & -0.001 & $(0.014)$ \\
\hline Female & $0.046^{* * *}$ & $(0.013)$ & 0.002 & $(0.009)$ & $0.047^{* * *}$ & $(0.015)$ \\
\hline Age & $0.007^{* * *}$ & $(0.002)$ & $0.004 * * *$ & $(0.001)$ & $0.007 * * *$ & $(0.002)$ \\
\hline Age squared & $-0.000^{* *}$ & $(0.000)$ & $-0.000^{* *}$ & $(0.000)$ & $-0.000^{* *}$ & $(0.000)$ \\
\hline Low income & Omit & & & & & \\
\hline Mid-income & -0.024 & $(0.021)$ & -0.012 & $(0.012)$ & -0.027 & $(0.022)$ \\
\hline High income & $-0.051^{* *}$ & $(0.020)$ & -0.005 & $(0.011)$ & $-0.053^{* * *}$ & $(0.019)$ \\
\hline Border proximity & -0.025 & $(0.034)$ & 0.005 & $(0.009)$ & -0.011 & $(0.032)$ \\
\hline Evasion border proximity & $0.089 * * *$ & $(0.032)$ & $0.059 * * *$ & $(0.012)$ & $0.055^{* *}$ & $(0.024)$ \\
\hline Low price border proximity & 0.047 & $(0.033)$ & 0.014 & $(0.011)$ & 0.029 & $(0.029)$ \\
\hline Serbia & Omit & & & & & \\
\hline Albania & 0.071 & $(0.047)$ & $0.068 * * *$ & $(0.024)$ & 0.062 & $(0.060)$ \\
\hline North Macedonia & -0.048 & $(0.065)$ & 0.024 & $(0.048)$ & -0.091 & $(0.108)$ \\
\hline Montenegro & $0.558 * * *$ & $(0.063)$ & & & $0.534 * * *$ & $(0.105)$ \\
\hline Bosnia and Herzegovina & $0.387^{* * *}$ & $(0.117)$ & & & $0.414^{* * *}$ & $(0.054)$ \\
\hline Kosovo & -0.030 & $(0.051)$ & $-0.196 * * *$ & $(0.006)$ & -0.059 & $(0.085)$ \\
\hline Observations & 2495 & & 1667 & & 2495 & \\
\hline
\end{tabular}

Source: Authors' calculations based on the Survey on Tobacco Consumption in Southeastern Europe (STC-SEE) data.

Figures in the table present the marginal effect of increasing the independent variable by one unit on the unit change in the dependent variable. Robust SEs in parentheses.

${ }^{*} \mathrm{P}<0.1 ;{ }^{* *} \mathrm{p}<0.05 ;{ }^{* *} \mathrm{p}<0.01$.

MC, manufactured cigarette; NSIP, non-street illegal purchase. 
our results. Finally, another robustness check is presented in specification S3 in which we again use full sample and equation (1) as in specification S1, only instead of a threshold of $50 \mathrm{~km}$, a threshold of $40 \mathrm{~km}$ is used to identify municipality in proximity to other countries .

The first important result indicates that in s-regions where there is a higher share of illicit purchases at legal points of sale in total illicit MC, there is a higher likelihood that the person is consuming illicit MC rather than legal one. In other words, if institutions have lower ability to regulate distribution and sales of tobacco at legal points of sale, this increases the likelihood of tax evasion. This effect is marginally significant in S1 and S3, where a 10 percentage points higher share of NCIP increases the likelihood of tax evasion by about 1.5 percentage points. The effect is the strongest in the case where countries with the highest tax evasion rates are excluded from the sample (S2).

The results further suggest that living in municipalities near countries with higher evasion rates increases the likelihood of tax evasion. This effect is significant in all the models, and the results suggest that living in close proximity to a country with a higher evasion rate increases the likelihood of tax evasion between 5.5 and 9 percentage points. On the other hand, the effect of living in municipalities that are in close proximity to countries with lower prices is not significant. Furthermore, the effect of living in other border areas is also not statistically significant.

Additionally, the results suggest that women, the elderly and those with lower income have a higher likelihood of MC tax evasion. Women are about 4.5 percentage points more likely than men to evade taxes; and evasion increases with age, however, at a diminishing rate. People from households with high income are less likely to evade taxes by about 5 percentage points when compared with other income groups. After initial estimates, the effects of educational level were not significant in any of the models and were dropped to increase the degrees of freedom in the models. Finally, s-regional differences in prices of legal MC do not have an impact on MC tax evasion. The last result is very important as it goes against the tobacco industry argument that increasing taxes and prices of tobacco products is one of the causes behind the increase of illicit trade.

Online supplemental table1 (annex 1) presents the estimation of the HR tax evasion model in the WB region. Since all HR products from Montenegro (13 observations) fall under the definition of evasion they are excluded from the estimation, as they would predict the positive outcome perfectly. The analysis suggests that the significant determinants of HR tax evasion in the WB regional model are age and gender, with older HR users and women more likely to evade taxes; as well as household income per capita, with persons from high-income households less likely to evade taxes. Contrary to the MC tax evasion model, share of NSIP and proximity to the border with a country that has a higher tax evasion rate (or any other country) are not significant predictors of HR evasion.

\section{DISCUSSION AND CONCLUSIONS}

Public data on tobacco tax evasion in the WB region are very limited and rarely transparent. In this study, unique data obtained from a recent survey on tobacco consumption in WB countries are used to estimate the size of the illicit tobacco market and to assess the impact of different factors on the probability of tax evasion in six WB countries. To the best of the researchers' knowledge, this is the first study that provides comparable estimates of the size of the illicit tobacco market in the WB region, as well as on the factors that affect it.
The results show that $20.4 \%$ of smokers in the WB region smoke illicit tobacco. This share is strikingly higher for HR smokers-at $86.7 \%$, while for the MC smokers this share is much lower-at $8.6 \%$ on average. The significantly higher share of illicit tobacco among HR smokers is due to difference in dominant type of evasion for two products. For HR, predominant type of evasion is the so-called 'genuine DNP' (without health warning or tax stamp) sold on the street or open air market, while for MC these are 'illicit whites' (without tax stamp but with health warnings). It should also be noted that MCs have a significantly higher smoking prevalence $(32.8 \%$, as compared with $6.3 \%$ for $\mathrm{HR}$ ), and therefore the total number of $\mathrm{MC}$ and HR smokers who smoke illicit tobacco is roughly the same (about $4 \%$ of the total population in WB countries). For both products, women and older smokers are more likely to smoke illicit tobacco, while smokers from high-income households are less likely to do so. Women and older smokers' higher likelihood of illicit consumption could be due to lower personal incomes of these groups within the household (unlike the income variable that accounts for household-level income differences). Lower income for women is in line with persisting gender pay gap in the region, ${ }^{25}$ while older persons are more likely to retire and have lower income at their disposal.

There are also significant differences in MC tax evasion between WB countries. MC tax evasion is the highest in Montenegro, where $61.2 \%$ of MC smokers use illicit MC, and in $\mathrm{BiH}$, with $18.6 \%$. In all other WB countries-Albania, Kosovo, North Macedonia, and Serbia-less than 6\% of MC users smoke illicit MC. The highest evasion in Montenegro is in line with international non-governmental reports underlining Montenegro the entry point of the illicit tobacco. ${ }^{26}$ As mentioned above, the main type of MC evasion is 'illicit whites'-cigarette packs which have health warnings (typically in foreign language), suggesting that the source of this type of evasion was smuggling.

Results further indicate that MC tax evasion is higher in s-regions with higher levels of non-street illicit purchases, indicating that failing to prevent the distribution and sale of illicit tobacco in legal points of sale contributes to higher MC tax evasion. From a wider point of view, this result indicates that the differences in institutional capacities to tackle illicit trade are behind the differences in MC evasion rates. Additionally, MC smokers from municipalities that are in close proximity to countries with significantly higher evasion rates (Montenegro and $\mathrm{BiH}$ ) are more likely to evade taxes. This shows that a certain spillover effect is at play, as the physical proximity to an area with a high level of tax evasion increases the likelihood of evasion. This result is in line with the reports that Montenegro's harbour bar is an international cigarette smuggling point of entry from where illicit products can be further distributed. ${ }^{26}$ Finally, and importantly, we show that the level of MC prices has no effect on the evasion, contrary to the arguments from the tobacco industry that higher taxes and prices of tobacco products would lead to higher levels of evasion.

On the other hand, HR tobacco tax evasion is very high in all the countries, with $86.7 \%$ of HR users evading taxes on average. Previous research has indicated that HR tobacco is used as a cheaper substitute for $\mathrm{MC}$ in $\mathrm{WB}$, and findings from this study suggest that at least part of the reason that HR tobacco is cheaper is the fact that smokers are not paying taxes on this product. ${ }^{11}$ Therefore, enforcement of taxation on HR tobacco would increase its price and weaken its potential to be used as a cheaper substitute for MC. Results also suggest that HR tax evasion is present in all regions of WB countries, regardless of their proximity to other countries or the local degree of strict 
control on legal points of sale, which suggests that, unlike for MC, the differences in HR tax evasion are not related to 'import' of illicit products from other countries, or institutional factors described by the share of NSIP. Anecdotal evidence from the pictures provided with the survey (only for a part of the sample) indicates illicit $\mathrm{HR}$ is purchased in unmarked transparent plastic bags, suggesting that this type of tobacco is purchased directly from tobacco growers or immediate traders. This type of trade seems to be unofficially tolerated by the governments to preserve social stability among the producers and smokers who cannot afford MC. As illicit HR is almost completely purchased on the streets or in open air or green markets $(92.0 \%$, compared with $66.3 \%$ of illicit MC), institutional factors behind $\mathrm{HR}$ are related to regulation of sale in open air or green markets.

\section{Policy recommendations}

When increasing taxes as an instrument of tobacco control policy, which is required for the EU accession process, governments should put additional effort into strengthening institutional capacities to tackle illicit tobacco trade. Law and fiscal enforcement institutions should ensure that all activities in the supply chain are adequately monitored, including production, distribution and sales of tobacco products. Countries should particularly focus on prevention of the illicit tobacco sold on the streets which makes up about $92.0 \%$ of HR and $66.3 \%$ of the MC illicit trade. Furthermore, countries should strengthen the monitoring of the distribution channels and enforce bans on the sale of illicit MC at legal points of sale, particularly in Kosovo and Montenegro where these shares are the highest.

As municipalities in close proximity to countries with high MC tax evasion are more likely to evade taxes on MC, improving regional coordination in the development and implementation of tobacco control policies-particularly for prevention of the illicit market-is essential to lowering the level of tax evasion in all WB countries. At the same time, all WB countries should ratify and implement the FCTC Protocol to Eliminate Illicit Trade in Tobacco Products.

The countries should also implement strict tobacco control measures to address the illicit HR tobacco market, the prevailing form of illicit tobacco trade in WB countries. In line with the FCTC Protocol to Eliminate Illicit Trade in Tobacco Products, adoption of new measures to tackle illicit HR tobacco should also deal with other actors in the supply chain (growers, manufacturers, exporters/importers, wholesalers and retailers).

\section{What this paper adds}

- This paper presents first estimates of the size and determinants of illicit tobacco consumption in Western Balkan region.

- Hand-rolled (HR) tobacco smokers are much more likely to smoke illicit tobacco than smokers of manufactured cigarettes (MC) $(86.7 \%$ vs $8.6 \%)$.

- While HR evasion varies relatively little across countries, MC evasion is much more frequent in Bosnia and Herzegovina and particularly Montenegro.

- Our research provides further evidence that higher tobacco taxes and prices do not increase illicit consumption, contrary to tobacco industry claims.

- Our research underlines the importance of strengthening institutional capacities and improving regional coordination to tackle illicit tobacco trade.

\section{Limitations}

Empirical strategy used to assess the determinants of illicit consumption in this paper is based on the quantitative methods (econometric estimates) and thus constrained by the data available. These constraints include (a) limited information available in the STC-SEE data on the role of the industry (as the data collected are focusing on consumers and consumption) and (b) unavailability of the s-region-level data (or even country-level data) on the impact of tobacco industry, smuggling or other factors. Therefore, these factors, which undoubtedly have an impact on the illicit practices, could not be analysed in the quantitative fashion and for this reason we do not claim their impact based on our results. Their impact is mentioned in the Introduction and Discussion and conclusions sections, in a descriptive way, underlining their role in the illicit trade in the WB region.

Contributors MV: conceptualisation, methodology, writing —original draft, review and editing, data analysis, guarantor. JZ: methodology, writing — annex 2, funding acquisition and project administration. OJ: methodology, writing —original draft preparation and annex 2. MD: methodology, writing —original draft, review and editing, annex 2. NTN, EP, DG, AG: methodology, writing —annex 2.

Funding This research was funded by the University of Illinois at Chicago's Institute for Health Research and Policy through its partnership with the Bloomberg Philanthropies (grant number 16809). Research of the authors from the Institute of Economic Sciences in Serbia has been additionally supported by the Ministry of Education, Science and Technological Development of Serbia.

Competing interests None declared.

Patient consent for publication Not required.

Ethics approval This study does not involve human participants. The survey was not conducted by the authors, but by the Deep Dive- a private, independent, fullservice social and market research consulting firm from Belgrade (Serbia). Deep Dive is a European Society for Opinion and Marketing Research (ESOMAR) member and as such was in charge for all ethical considerations and has obtained participants' permission. The usage of these data for research purposes was additionally approved by Data Centre Serbia for Social Sciences, national authority in the field of social sciences.

Provenance and peer review Not commissioned; externally peer reviewed.

Data availability statement Data are available upon reasonable request. Data used in this research were obtained from the 2019 Survey on Tobacco Consumption in Southeastern Europe (STC-SEE), which provides nationally representative data on smoking behaviour for adult population for six Western Balkan countries (Albania, Bosnia and Herzegovina, Kosovo, Montenegro, North Macedonia and Serbia). Data collection was coordinated by Deep Dive — a private, independent, full-service social and market research consulting firm, and under supervision of the Institute of Economic Sciences, Belgrade, Serbia. The data can be shared with third parties upon reasonable request.

\section{ORCID iDs}

Marko Vladisavljevic http://orcid.org/0000-0001-6020-1355

Jovan Zubović http://orcid.org/0000-0002-1717-2066

Olivera Jovanovic http://orcid.org/0000-0002-0676-4787

\section{REFERENCES}

1 Joossens L, Merriman D, Ross H, et al. The impact of eliminating the global illicit cigarette trade on health and revenue. Addiction 2010;105:1640-9.

2 Goodchild M, Paul J, Iglesias R, et al. Potential impact of eliminating illicit trade in cigarettes: a demand-side perspective. Tob Control; 112:tobaccocontrol-2020-055980.

3 Joossens L, Lugo A, La Vecchia C, et al. Illicit cigarettes and hand-rolled tobacco in 18 European countries: a cross-sectional survey. Tob Control 2014;23:e17-23.

4 Guindon GE, Driezen P, Chaloupka FJ, et al. Cigarette tax avoidance and evasion: findings from the International tobacco control policy evaluation (ITC) project. Tob Control 2014;23 Suppl 1:113-22.

5 Smith $K E$, Savell E, Gilmore AB. What is known about tobacco industry efforts to influence tobacco Tax? A systematic review of empirical studies. Tob Control 2013;22:e1.

6 JTI supports the announcement of reduction of excise taxes on cigarettes in Montenegro and BiH. Available: http://www.diplomacyandcommerce.rs/jti-supportsthe-announcement-of-reduction-of-excise-taxes-on-cigarettes-in-montenegro-andbih/ [Accessed 17 Sep 2021] 
7 Joossens L, Merriman D, Ross H. How eliminating the global illicit cigarette trade would increase Tax revenue and save lives. Paris: International Union Against Tuberculosis and Lung Disease, 2009.

8 Ross $\mathrm{H}$, Blecher E. Illicit trade in tobacco products need not hinder tobacco Tax policy reforms and increases. Tobacconomics white paper. Chicago: Tobacconomics, Health Policy Center, Institute for Health Research and Policy, University of Illinois at Chicago, 2019

9 Langley TE, Gilmore A, Gallagher A. Confronting illicit tobacco trade: a global review of country experiences. United Kingdom: Tackling illicit tobacco, World Bank, 2019. http://documents.worldbank.org/curated/en/677451548260528135/ConfrontingIllicit-Tobacco-Trade-a-Global-Review-of-Country-Experiences

10 International Agency for Research on Cancer (IARC). IARC handbooks for cancer prevention: effectiveness of Tax and price policies for tobacco control. Lyon: International Agency for Research on Cancer, 2011.

11 Vladisavljević M, Zubović J, Jovanović O. How do prices of manufactured cigarettes and roll-your-own tobacco affect demand for these products? tobacco price elasticity in southeastern Europe. Belgrade, Serbia: Institute of Economic Sciences, 2020. http:// tobaccotaxation.org/cms_upload/pages/files/203_regional_report_-_demand_price_ elasticity_-_topic_6_1410.pdf

12 Mikulić D, Buturac G. In what measure is public finance sustainability threatened by illicit tobacco trade: the case of Western Balkan countries. Sustainability 2020;12:401.

13 Hajdinjak M. \# 10 Smuggling in Southeast Europe. The Yugoslav wars and the development of regional criminal networks in the Balkans. Center for the Study of Democracy - CSD Reports, 2002. Available: https://www.ceeol.com/search/bookdetail id $=519984$

14 Sorensen JS. War as social transformation: wealth, class, power and an illiberal economy in Serbia. Civil Wars 2003;6:55-82.
15 Zaloshnja E, Ross H, Levy DT. The impact of tobacco control policies in Albania. Tob Control 2010;19:463-8.

16 Richter S, Wunsch N. Money, power, glory: the linkages between EU conditionality and state capture in the Western Balkans. J Eur Public Policy 2020;27:41-62.

17 Simpson C. Tackling smuggling in the Balkans: policy lessons. Forced Migration Review 2020;64:69-72.

18 World Health Organization (WHO). Global adult tobacco survey: Romania. Bucharest: Ministry of Health of Romania, 2012.

19 World Health Organization (WHO). Global adult tobacco survey: Greece, 2013. Athens: Ministry of Health of Greece, 2013.

20 World Health Organization (WHO). Global adult tobacco survey: turkey, 2012. Ankara: Public Health Institution of Turkey, 2014.

21 World Health Organization (WHO). Global adult tobacco survey: report Ukraine. Kiev: Ministry of Health of Ukraine, 2017.

22 World Health Organization (WHO). GATS Russian Federation: global adult tobacco survey, country report 2016. Moscow: Ministry of Health of the Russian Federation, 2018.

23 Stoklosa M, Ross H. Contrasting academic and tobacco industry estimates of illicit cigarette trade: evidence from Warsaw, Poland. Tob Control 2014;23:e30-4.

24 Driezen P, EUREST-PLUS Consortium onbehalfofthe. Cross-Border purchasing of cigarettes among smokers in six European countries: findings from the EUREST-PLUS ITC Europe surveys. Tob Prev Cessat 2019;5.

25 Vladisavljević M, Avlijaš S, Vujić S. Gender Wage Inequality in the Western Balkans. In: Inequalities during and after transition in central and eastern Europe. Palgrave Macmillan, London, 2015: 222-43.

26 Cigarette Smugglers find safe harbour in Montenegro, again. Available: https:// balkaninsight.com/2019/05/30/cigarette-smugglers-find-safe-harbour-in-montenegroagain/ 